\title{
Role of active oxygen, lipid peroxidation, and antioxidants in the pathogenesis of gastric mucosal injury induced by indomethacin in rats
}

T Yoshikawa, Y Naito, A Kishi, T Tomii, T Kaneko, S Iinuma, H Ichikawa, M Yasuda, $S$ Takahashi, M Kondo

\begin{abstract}
The roles of active oxygen, lipid peroxidation, and the antioxidative defence mechanism in gastric mucosal injury induced by treatment with indomethacin in rats were investigated. The total area of gastric erosions and concentration of lipid peroxides in the gastric mucosa increased with time after administration of indomethacin $(20 \mathrm{mg} / \mathrm{kg}$, orally). The $\alpha$ tocopherol:total cholesterol ratio in serum was significantly decreased and the activity of glutathione peroxidase, an important enzyme to scavenger of lipid peroxides, was inhibited by the administration of indomethacin. Treatments with superoxide dismutase and catalase inhibited the increases in gastric mucosal erosions and lipid peroxides in the gastric mucosa, and the reduction of serum $\alpha$-tocopherol. Treatment with these scavengers did not improve the decreased glutathione peroxidase activity. These findings suggest that active oxygen species and lipid peroxidation play an important part in the pathogenesis of gastric mucosal injury induced by indomethacin, and that the decreased glutathione peroxidase activity aggravated the injury due to accelerated accumulation of hydrogen peroxide and lipid peroxides in the gastric mucosal cell.

(Gut 1993; 34: 732-737)
\end{abstract}

Indomethacin, a non-steroidal anti-inflammatory drug (NSAID), is known to induce erosions and ulcers in the gastrointestinal tract. ${ }^{12}$ Although it has been proposed that a deficiency of endogenous prostaglandins due to inhibition of cyclooxygenase by indomethacin is involved in these effects, the exact pathogenic mechanism remains to be elucidated. ${ }^{3-5}$ Recent studies showed that a low dose of indomethacin or aspirin inhibited cyclooxygenase activity in the gastric mucosa of rats by $90 \%$ without causing any haemorrhagic erosions. ${ }^{6}$ Takeuchi et $a l^{7-9}$ postulated that the enhanced gastric motility induced by indomethacin causes microcirculatory disturbances that lead to increased microvascular permeability and cellular damage. Rainsford $^{10}$ also noted, with transmission electron microscopy, that microvascular injury was present during gastric mucosal injury produced by indomethacin. These reports suggested that inhibition of prostaglandin synthesis was unlikely to be the sole mechanism responsible for the gastric damage induced by indomethacin.

Much recent attention has been focused on the role of reactive oxygen species in mediating the microvascular disturbance that preceded gastric mucosal injury induced by several kinds of stress and ischaemia-reperfusion. ${ }^{112}$ Furthermore, lipid peroxidation mediated by oxygen free radicals is believed to be an important cause of destruction and damage to cell membranes, because polyunsaturated fatty acids of the cellular membranes are degraded by the lipid peroxidation with consequent disruption of membrane integrity. ${ }^{13}$ Membrane peroxidation can lead to changes in membrane fluidity and permeability, enhanced rates of protein degradation, and ultimately, cell lysis. We have already reported that lipid peroxidation plays a significant part in the pathogenesis of gastric mucosal lesions induced by water immersion restraint stress, burn shock, and ischemia-reperfusion. ${ }^{14-16}$ The present study was undertaken in rats to measure changes in lipid peroxides and antioxidants in serum samples and gastric mucosa after administration of indomethacin. Also, we investigated the effects of a superoxide radical scavenger (superoxide dismutase (SOD)), a hydrogen peroxide scavenger (catalase), and a hydroxyl radical scavenger (dimethylsulphoxide (DMSO)) on gastric mucosal injury and lipid peroxide formation induced by giving indomethacin to rats, and the effects of a combination of SOD and catalase on indomethacin induced changes in antioxidants.

\section{Materials and methods}

Male Sprague-Dawley rats, weight range 190$210 \mathrm{~g}$ from Keari Co Ltd, Osaka, were used. The animals were deprived of food but allowed free access to water for 24 hours before the experiment. Gastric haemorrhagic damage was induced by oral administration of indomethacin (Sigma Chemical Co, St Louis, MO) at a dose of $20 \mathrm{mg} / \mathrm{kg}$, suspended in $0.5 \%$ carboxymethylcellulose solution with a few drops of Tween 80 in a volume of $0.5 \mathrm{ml} / 100 \mathrm{~g}$ body weight. In the control groups, the rats received an equivalent volume of the vehicle.

\section{EXPERIMENTAL PROCEDURE}

Time course study of indomethacin induced gastric mucosal injury

Groups of indomethacin treated rats were killed three or six hours after administration of indomethacin. Animals were killed by exsanguination via the abdominal aorta under inhaled ether anaesthesia. The stomachs were removed, 
opened along the greater curvature, and examined under a dissecting microscope with a square grid for lesions developed in the glandular portion. The extent of the gastric damage was expressed as the total area $\left(\mathrm{mm}^{2}\right)$ of haemorrhagic erosion. The gastric mucosa was scraped off by means of two glass slides on ice, and homogenised with $1.5 \mathrm{ml}$ of $10 \mathrm{mM}$ potassium phosphate buffer (pH 7.8) containing $30 \mathrm{mM}$ $\mathrm{KCl}$ in a Potter-Elvehjem homogeniser, to measure concentrations of lipid peroxides and tocopherols. To measure the activities of SOD and glutathione peroxidase, the homogenates were sonicated over ice for two minutes. The sonicated samples were centrifuged at $20000 \mathrm{~g}$ for 20 minutes and the supernatants were stored frozen at $-80^{\circ} \mathrm{C}$ until assay.

\section{Effects of scavengers of active oxygen on} indomethacin induced gastric mucosal injury

Activity of SOD in serum reached a maximum of about $100 \mathrm{U} / \mathrm{ml}$ after 150 minutes when SOD was subcutaneously injected at a dose of 50000 $\mathrm{U} / \mathrm{kg} .{ }^{17}$ Therefore, the interval of injection is important to maintain effective plasma SOD activity. To assess the effect of SOD and catalase, recombinant human $\mathrm{Cu}, \mathrm{Zn}-\mathrm{SOD}$ (Nippon Kayaku Co Ltd, Tokyo) at a dose of $50000 \mathrm{U} / \mathrm{kg}$, or catalase from bovine liver (Sigma Chemical Co, St Louis, MO) at a dose of 90000 $\mathrm{U} / \mathrm{kg}$ dissolved in $1 \mathrm{ml}$ of physiological saline, or both were injected subcutaneously one hour before and three hours after giving indomethacin. The same amount of physiological saline was injected in the same manner into the control rats. Dimethylsulphoxide (Wake Pure Chemical Co, Osaka) at a dose of $550 \mathrm{mg} / \mathrm{kg}$ diluted in $0.5 \mathrm{ml}$ of physiological saline was administered by intraperitoneal injection 30 minutes before and three hours after indomethacin to keep DMSO at a sufficiently high concentration to force efficient scavenging of hydroxyl radicals. Control animals received 0.5 $\mathrm{ml}$ of physiological saline in the same manner. Six hours after indomethacin treatment the rats were killed by exsanguination via the abdominal aorta and the extent of gastric damage was expressed as the total area of haemorrhagic erosion. The concentration of lipid peroxides in the gastric mucosa was also measured.

\section{Effect of SOD plus catalase on indomethacin induced changes in antioxidants}

The effects of treatment with SOD plus catalase on the activities of SOD and glutathione peroxidase in gastric mucosa, on the concentration of $\alpha$-tocopherol in gastric mucosa and serum samples and on the concentrations of reduced and oxidized glutathione after administration of indomethacin were investigated. Rats received SOD (recombinant human $\mathrm{Cu}, \mathrm{Zn}-\mathrm{SOD}$ ) and catalase at the same doses as previously described, by subcutaneous injection one hour before and three hours after indomethacin administration. Control animals received the same amount of physiological saline. Gastric mucosal homogenates were prepared as des- cribed earlier, serum samples were collected, and the activities or the concentrations of antioxidants were measured by the methods described next.

\section{ASSAYS}

Concentrations of thiobarbituric acid (TBA)reactive substances, an index of lipid peroxidation, were measured in serum samples by the method of Yagi, ${ }^{18}$ and the concentrations in tissue homogenates were measured according to Ohkawa et al. ${ }^{19}$ The concentration of the TBAreactive substances were expressed as nmol malodialdehyde. Thiobarbituric acid (BDH Chemicals, Poole, England) and 1,1,3,3trimethoxypropane (Tokyo Kasei Co, Tokyo) were used for the TBA assay, and all other chemicals were of reagent grade. Protein concentration in the gastric mucosal homogenates was measured by the method of Lowry et al..$^{20}$ The concentration of $\alpha$-tocopherol in serum samples and gastric mucosa was measured by the method of Abe $e t a l^{21}$ with a high speed LC-6A liquid chromatograph (Shimazu Co, Kyoto). To eliminate the influence of lipids, the ratio of $\alpha$-tocopherol:total cholesterol in serum samples was determined. The serum cholesterol concentration was assayed according to the method of Richmond..$^{22}$ The activity of SOD was measured by a recently developed chemiluminescence assay, ${ }^{23}$ which involved inhibition of a Cypridina luciferin analog with chemiluminescence dependent on superoxide generated by the hypoxanthine-xanthine oxidase system. Recombinant human $\mathrm{Cu}, \mathrm{Zn}$-SOD (a gift from Nippon Kayaku Co, Tokyo) was used as a standard and its activity was determined by the cytochrome $\mathrm{c}$ method. Activity of SOD in tissue was expressed as $\mathrm{U} / \mathrm{mg}$ protein. The activity of glutathione peroxidase in the gastric mucosa was assayed spectrophotometrically by the method of Gïnzler $e t a l^{24}$ with $t$-butyl hydroperoxidase as the substrate. This assay is based on the oxidation of reduced glutathione by glutathione peroxidase coupled to the oxidation of NADPH by glutathione reductase. The rate of NADPH oxidation was monitored photometrically. For the glutathione assay, the stomach was perfused intraluminally with 5\% sulphosalicylic acid and then homogenised in $10 \mathrm{vol} / \mathrm{g}$ of the same solution. The tissue homogenate was centrifuged for five minutes at $10000 \mathrm{~g}$, and then the supernatant was stored on ice until use. The amount of reduced glutathione (GSH) was measured by the method of Griffith ${ }^{25}$ and the amount of oxidised glutathione (GSSG) was measured by masking GSH with N-ethylmalemide (NEM).

\section{STATISTICAL ANALYSIS}

Results are presented as means (SEM). For statistical analysis, the tests used were the Bartlett test for homogenicity of variance, Kruskal-Wallis analysis of variance for effects in time and comparison of differences between control and groups treated with scavengers, and the Mann-Whitney test for individual comparison of the group means. Differences between the 
Figure 1: Total area of gastric erosions after indomethacin. Values are mean (SEM) of nine experiments. $\star \star \star p<0.00$ compared with the values before indomethacin.

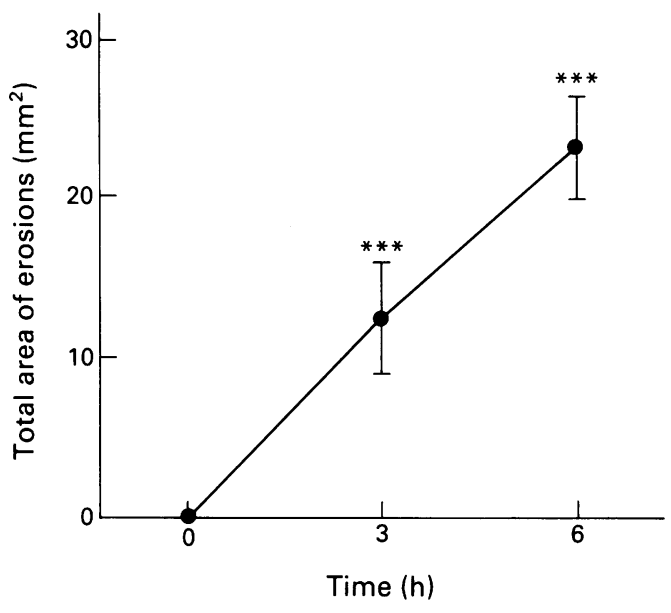

groups were considered significant if the $p$ value was less than 0.05 .

\section{Results}

CHANGES IN MUCOSAL INJURY, LIPID PEROXIDES, AND ANTIOXIDANTS AFTER ADMINISTRATION OF INDOMETHACIN

Gastric haemorrhagic erosions increased with time after administration of indomethacin. The total area of erosions at three hours and six hours after the administration was $12.6(3.5) \mathrm{mm}^{2}$ and $23 \cdot 2(3 \cdot 2) \mathrm{mm}^{2}$ respectively (Fig 1 ). The lesions were linear or dotted in shape, and were often located on the upper part of the mucosal folds.

TBA-reactive substances in the gastric mucosa, an index of lipid peroxidation, increased significantly $(\mathrm{p}<0.01)$ from a basal concentration of mean (SEM) $0.521(0.014)$ $\mathrm{nmol} / \mathrm{mg}$ protein to $0.626(0.019) \mathrm{nmol} / \mathrm{mg}$ protein and $0.663(0.036) \mathrm{nmol} / \mathrm{mg}$ protein three hours and six hours after administration of indomethacin respectively. Indomethacin did not affect the level of TBA-reactive substances in serum, however (Fig 2). $\alpha$-Tocopherol in serum samples, but not in the gastric mucosa, decreased significantly $(p<0.05)$ with time after indomethacin administration. The $\alpha$-tocopherol: cholesterol ratio in serum decreased to 4.99 $(0.19) \times 10^{-3}$ and $4.96(0.26) \times 10^{-3}$ at three hours and six hours after indomethacin administration respectively, from $5.88(0 \cdot 24) \times 10^{-3}$ measured before the experiment (Fig 3).

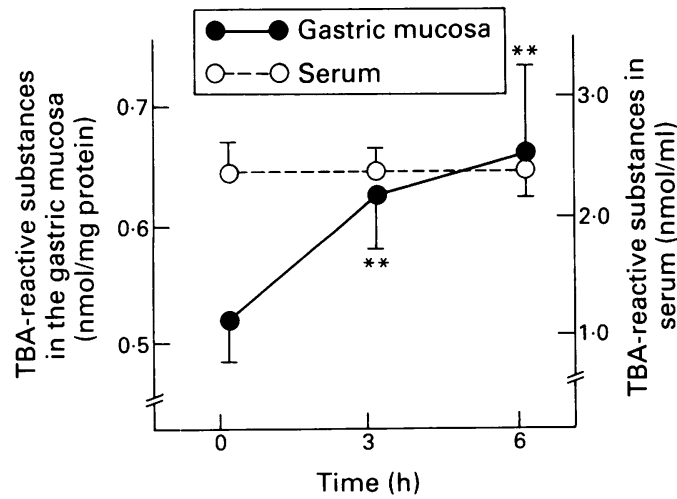

Figure 2: Thiobarbituric acid (TBA)-reactive substances in the gastric mucosa and serum after indomethacin. Values are mean (SEM) of six experiments. ${ }^{\star \star} p<0.01$ compared with the values before indomethacin.

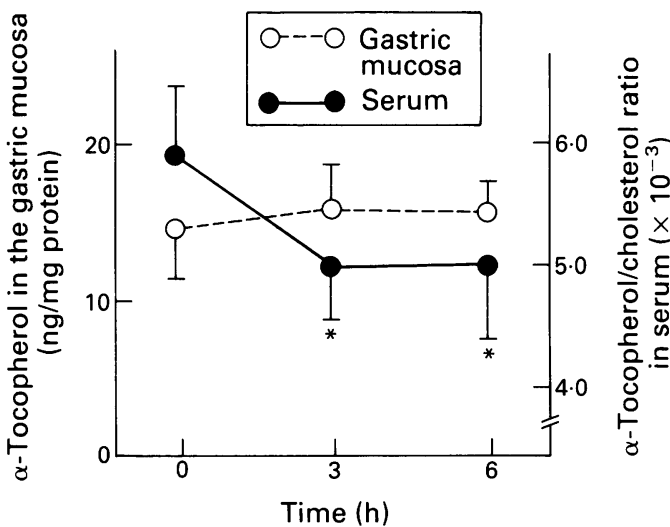

Figure 3: $\alpha$-Tocopherol in the gastric mucosa and serum after indomethacin. Values are mean (SEM) of six experiments. ${ }^{\star} p<0.05$ compared with the values before indomethacin.

The activities of SOD and glutathione peroxidase in the gastric mucosa of rats treated with $0.5 \%$ control carboxymethylcellulose solution were $14.5(0.48) \mathrm{U} / \mathrm{mg}$ protein and $288.0(30.2)$ $\mathrm{mU} / \mathrm{mg}$ protein respectively. Intragastric administration of indomethacin did not affect the activities of SOD in the gastric mucosa at three or six hours after indomethacin. The activity of glutathione peroxidase at six hours after the administration was significantly reduced $(\mathrm{p}<0.05)$ to $195.6(15.6) \mathrm{mU} / \mathrm{mg}$ protein (Fig 4). Concentrations of reduced and oxidised forms of glutathione in the gastric mucosa of control rat stomachs were $1.49(0 \cdot 11) \mu \mathrm{g} / \mathrm{g}$ tissue and $5.4(4.4) \mathrm{ng} / \mathrm{g}$ tissue respectively. Six hours after administration of indomethacin the level of reduced glutathione was significantly decreased $(\mathrm{p}<0.001)$ to $46.9 \%$ of the control value, but the level of oxidised glutathione was not affected.

\section{EFFECTS OF ACTIVE OXYGEN SCAVENGERS ON} INDOMETHACIN INDUCED GASTRIC MUCOSAL INJURY (Table)

The mean (SEM) of the total area of gastric haemorrhagic erosions in control animals receiving subcutaneous physiological saline was $26 \cdot 8$ (4.5) $\mathrm{mm}^{2}$ at six hours after indomethacin administration. SOD and a combination of SOD and catalase significantly reduced $(p<0.05)$ the lesion area to $46.6 \%$ and $49.6 \%$ of the mean of control values. The lesion area of the group treated with catalase was not significantly different from that of the control rats. The increase in

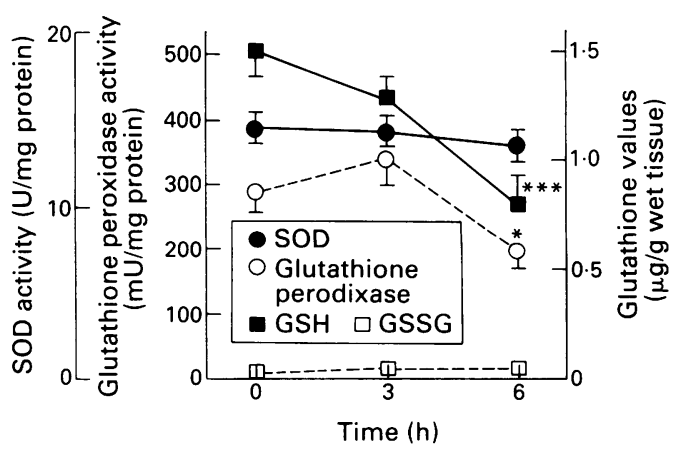

Figure 4: Activities of superoxide dismutase $(S O D)$ and glutathione peroxidase and the amounts of reduced and oxidised glutathione (GSH and GSSG) in gastric mucosa after indomethacin. Values are mean (SEM) of six experiments. ${ }^{\star} p<0.05$ and ${ }^{\star \star \star} p<0.001$ compared with the values before indomethacin. 
Effects of superoxide dismutase (SOD), catalase, SOD plus catalase, and dimethylsulphoxide (DMSO) on total area of haemorrhagic erosions and thiobarbituric acid (TBA) reactive substances in the gastric mucosa at six hours after giving indomethacin

\begin{tabular}{llll}
\hline & $\begin{array}{l}\text { No of } \\
\text { animals }\end{array}$ & $\begin{array}{l}\text { Lesion } \\
\text { area } \\
\left(\mathrm{mm}^{2}\right)\end{array}$ & $\begin{array}{l}\text { TBA-reactive } \\
\text { substances }(\text { nmol/mg } \\
\text { protein) }\end{array}$ \\
\hline Control 1 & 6 & $26 \cdot 8(4 \cdot 5)$ & $0.663(0.030)$ \\
SOD & 6 & $12 \cdot 5(1.6)^{\star}$ & $0.589(0.085)$ \\
Catalase & 6 & $18.5(4 \cdot 7)$ & $0.575(0.097)$ \\
SOD plus catalase & 6 & $13.3(3.8)^{\star}$ & $0.559(0.035)^{\star}$ \\
Control 2 & 9 & $22 \cdot 8(3.5)$ & $0.715(0.069)$ \\
DMSO & 9 & $12 \cdot 1(2 \cdot 4)^{\star}$ & $0.524(0.048)^{\star}$ \\
\hline
\end{tabular}

Values are mean (SEM) for that group. ${ }^{\star} \mathrm{p}<0.05$ by MannWhitney test for the difference between presented value and that of rats treated with physiological saline as the control.

TBA-reactive substances in the gastric mucosa at six hours after indomethacin administration was significantly inhibited by combination treatment with SOD and catalase, but not by treatment with SOD or catalase alone.

The total areas of gastric erosion six hours after indomethacin administration were $22 \cdot 8$ (3.5) $\mathrm{mm}^{2}$ in the control rats receiving intraperitoneal saline and $12 \cdot 1(2 \cdot 4) \mathrm{mm}^{2}$ in the DMSO group. There was a significant difference $(p<0.05)$ in the lesion area between the two groups. The increase in TBA-reactive substances was also significantly inhibited $(p<0.05)$ by intraperitoneal treatment with DMSO.

EFFECTS OF SOD PLUS CATALASE ON INDOMETHACIN INDUCED CHANGES IN ANTIOXIDANTS

The decrease in the $\alpha$-tocopherol:total cholesterol ratio in the serum of the control (indomethacin only) rats recovered to that of the normal (untreated) rats after treatment with SOD and catalase (Fig 5). There was no significant difference in the concentration of $\alpha$-tocopherol in the gastric mucosa among the normal, the control, and the SOD plus catalase groups. Figure 6 shows that indomethacin significantly $(p<0.05)$ reduced the activity of glutathione peroxidase in the gastric mucosa in groups treated and not treated with SOD and catalase. There were no significant differences in the activity of SOD among these three groups. Even when SOD

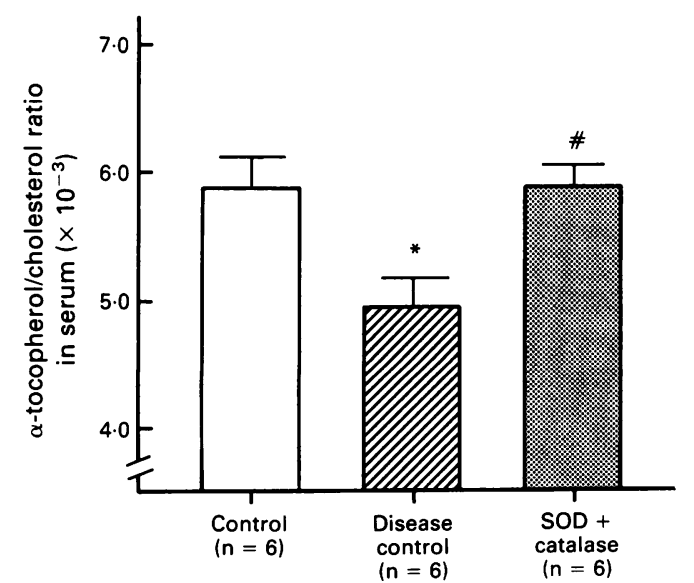

Figure 5: Superoxide dismutase (SOD) plus catalase treatment on the $\alpha$-tocopherol:total cholesterol ratio in serum six hours after indomethacin. Values are mean (SEM). ${ }^{\star} p<0.05$ compared with normal control group and $\# p<0.05$ compared with the disease control group treated with physiological saline.

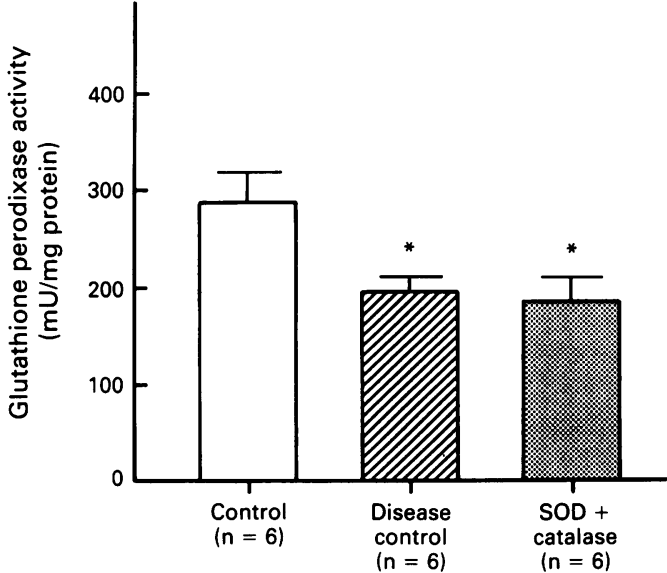

Figure 6: Superoxide dismutase (SOD) plus catalase treatment on glutathione peroxidase activity in the gastric mucosa six hours after indomethacin. Values are mean (SEM). ${ }^{\star} p<0.05$ compared with normal control group.

was administered, its activity in the gastric mucosa did not increase. The level of reduced glutathione in the gastric mucosa was $1.49(0 \cdot 11)$ $\mu \mathrm{g} / \mathrm{g}$ tissue in the untreated group, $0.70(0.15)$ $\mu \mathrm{g} / \mathrm{g}$ tissue in the control group, and $1 \cdot 10$ $(0.07) \mu \mathrm{g} / \mathrm{g}$ tissue in the SOD plus catalase group respectively (Fig 7). There were significant differences between the normal group and the control group $(p<0.001)$, and between the control group and the SOD plus catalase group $(\mathrm{p}<0.05)$.

\section{Discussion}

Our present studies implicate active oxygen and lipid peroxidation in the pathogenesis of gastric mucosal injury induced by indomethacin. Itoh and Guth" first showed that SOD could significantly protect against gastric mucosal injury induced by haemorrhageic shock for 20 minutes and retransfusion in rats. We also produced an ischaemia-reperfusion injury model with rat stomach, and found a suppression of both gastric mucosal lesions and increased lipid peroxidation by SOD and catalase. ${ }^{16}$ Also, Perry $e t$ al ${ }^{12}$ have shown that a hydroxyl radical scavenger, DMSO, significantly reduced both ${ }^{51} \mathrm{Cr}$-red cell loss and the less sensitive index of gastric

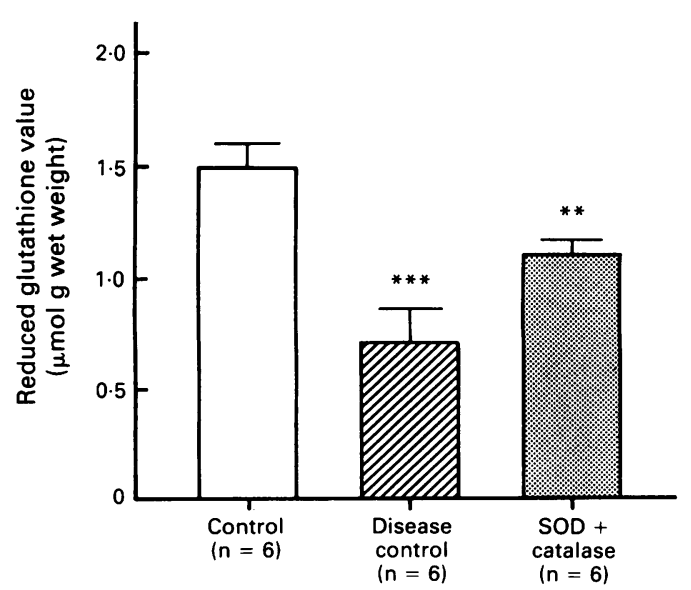

Figure 7: Superoxide dismutase (SOD) plus catalase treatment on reduced glutathione concentration in the gastric mucosa six hours after indomethacin. Values are mean (SEM). ${ }^{\star \star} p<0.01$ and ${ }^{\star \star} p<0.001$ compared with normal control. 
mucosal injury, ${ }^{125}$ I-albumin loss produced by ischaemia. Cochran et $a l^{26}$ and Terano et $a l^{27}$ also reported that DMSO inhibited gastric mucosal injury induced by stress or ethanol. Rats received intraperitoneal DMSO at a dose of 550 $\mathrm{mg} / \mathrm{kg}$, because previous work had shown that peak concentrations occur within 30 minutes and that the average half life is about six hours at that dose and route of administration. ${ }^{27}$ In the present study, indomethacin produced gastric haemorrhagic erosions and increased TBA-reactive substances, which are indicators of lipid peroxidation, in the gastric mucosa with time after administration. Also, lipid peroxide accumulation closely paralleled the development of gastric mucosal injury. This indicates that lipid peroxidation plays a significant part in the pathogenesis of the gastric mucosal lesions induced by indomethacin, as well as gastric injuries produced by burn shock, ${ }^{15}$ water immersion restraint stress, ${ }^{14}$ and ischaemia-reperfusion..$^{16}$ Also, the treatment with SOD, SOD plus catalase, and DMSO significantly inhibited the pathological changes induced by indomethacin. As is well known, the superoxide radical can interact with hydrogen peroxide in the presence of iron to generate the hydroxyl radical, which is thought to be the most toxic reactant and to abstract methylene hydrogen atoms from polyunsaturated fatty acids, which initiates lipid peroxidation. The protection by radical scavengers, therefore, suggests that lipid peroxidation mediated by oxygen radicals, especially hydroxyl radicals, plays an important part in the formation and development of the gastric mucosal lesions induced by indomethacin.

The source of oxygen radicals in gastric mucosal injury induced by indomethacin in rats is not clear. Recent studies, however, suggest a possible role of neutrophils in the early pathogenic process. The severity of gastric damage induced by indomethacin can be significantly reduced by prior depletion of circulatory neutrophils and by treatment with a monoclonal antibody against the CD18 leucocyte adhesion molecule. ${ }^{28}{ }^{29}$ Both SOD and DMSO have been shown to diminish leucocyte adherence in microvessels. ${ }^{30}$ Therefore, the protective action of these scavengers in this model is consistent with the proposal by Wallace et al..$^{28} 29$

Vitamin E, a lipid soluable antioxidant, interacts with oxygen and lipid radicals and prevents the propagation of free radical lipid peroxidation. Our previous work showed that the concentrations of $\alpha$-tocopherol decreased both in serum samples and in gastric mucosa during ischaemiareperfusion injury in rats, ${ }^{32}$ which suggests that $\alpha$-tocopherol was consumed in the process of lipid peroxidation mediated by oxygen radicals in ischemia-reperfusion to prevent the development of tissue damage. When the radicals are formed initially in the aqueous phase of whole blood, the water soluble antioxidants in the plasma such as vitamin $C$ and plasma vitamin $E$ participate in the primary defence and later vitamin $E$ in the erythrocyte membrane decreases. ${ }^{33}$ In the present study, $\alpha$-tocopherol in the serum but not that in the gastric mucosa significantly decreased with time after indomethacin administration, and also the decrease of $\alpha$-tocopherol in the serum was returned to the normal range by concomitant treatment with SOD and catalase. Our previous study showed that subcutaneously injected SOD was predominantly localised in extracellular compartments, ${ }^{17}$ and our present study showed that the SOD activity in intracellular compartments of the rat stomach did not increase after the subcutaneous injection of human SOD. Thus we speculated that a free radical reaction occurred first in the extracellular space after indomethacin administration, and SOD and catalase after the concentration of $\alpha$-tocopherol by their actions as scavengers of superoxides and inhibitors of the production of hydroxyl radicals.

Glutathione is an important constituent of intracellular protective mechanisms against a number of noxious stimuli including oxidative stress. Reduced glutathione is known as a major low molecular weight scavenger of free radicals in cytoplasm. On the other hand, the antioxidant activity of GSH peroxidase is coupled with the oxidation of GSH to GSSG, which can subsequently be reduced by GSH reductase with NADPH as the reducing agent. Concentration of glutathione is exceedingly high in the glandular stomach compared with concentrations in other portions of the gastrointestinal tract or in most other organs. ${ }^{34}$ Boyd et $a l^{35}$ reported that depletion of gastric glutathione by diethyl maleate produced gastric ulceration. Mutoh et $a l^{36}$ showed that intracellular glutathione was mainly responsible for protecting against gastric cell injury induced by ethanol. These findings suggest that in the gastric mucosa free radicals or lipid peroxides are injurious offensive factors and GSH is a protecting defensive factor. Depletion of glutathione results in enhanced lipid peroxidation $^{37}$ and excessive lipid peroxidation can cause increased GSH consumption. ${ }^{38}$ The decrease in GSH in our study was accompanied by an increase in lipid peroxides measured as a TBA-reactive substance in the gastric mucosa. The content of GSSG, however, showed no significant increases in response to the depletion of GSH and the activity of GSH peroxidase was significantly inhibited by indomethacin administration, which indicates that GSH was consumed during the reaction with oxygen radicals, organic radicals, and peroxide radicals.

Glutathione peroxidase is important in the elimination of hydrogen peroxide and lipid hydroperoxides in the gastric mucosal cell. Thus inhibition of this enzyme may result in the accumulation of hydrogen peroxide with subsequent oxidation of lipids. The GSH peroxidase actvity of this study was decreased six hours after indomethacin administration and its activity could not be recovered by the elimination of oxygen radicals. These findings suggest that indomethacin itself, or depletion of prostaglandins, inhibits GSH peroxidase activity of the gastric mucosa. Our findings are in line with those of Banerjee, ${ }^{39}$ who recently showed the inhibition of peroxidase activity in the mitochondrial fraction of rat gastric mucosa by indomethacin.

In summary, the results indicate that excessive generation of oxygen radicals in the extracellular space and the depletion of GSH in conjunction 
with inhibition of GSH peroxidase activity is responsible for the oxidative tissue damage of gastric mucosa after administration of indomethacin.

1 Djahanguiri B. The production of acute gastric ulceration by indomethacin in the rat. Scand $\mathcal{F}$ Gastroenterol 1969; 4 : $265-7$.

2 Fries JF, Miller SR, Spitz BW, Williams CA, Hubert HB, Block DA. Toward an epidemiology of gastropathy associated with nonsteroidal antiinflammatory drug use. Gastroenterology 1989; 96: 647-55.

3 Whittle BJR. Temporal relationship between cyclooxygenase inhibition, as measured by prostaglandin biosynthesis, and the gastrointestinal damage induced by indomethacin in the rat. Gastroenterology 1981;80: 94-8.

4 Rainsford KD, Willis C. Relationship of gastric mucosal damage induced in pigs by antiinflammatory drugs to their effects on prostaglandin production. Dig Dis Sci 1982; 27 : 624-35.

5 Kobayashi K, Arakawa T, Satoh H, Fukuda T, Nakamura H. Effect of indomethacin, tiaprofenic acid and dicronfenac on rat gastric mucosal damage and content of prostacyclin and rat gastric mucosal damage and content of prostac

6 Ligmusky M, Golanska EM, Hansen DG, Kauffman GL. Aspirin can inhibit gastric mucosal cyclooxygenase without causing lesions in rats. Gastroenterology 1983; 84: 756-61.

7 Takeuchi K, Ueki S, Okabe S. Importance of gastric motility in the pathogenesis of indomethacin-induced gastric lesions in rats. Dig Dis Sci 1986; 31: 1114-21.

8 Ueki S, Takeuchi K, Okabe S. Gastric motility is an important factor in the pathogenesis of indomethacin-induced gastric mucosal lesions in rats. Dig Dis Sci 1988; 33: 209-16.

9 Takeuchi K, Okada M, Ebara S, Osano H. Increased microvascular permeability and lesion formation during gastric hypermotility caused by indomethacin and 2-deoxy-Dhypermotility caused by indomethacin and 2-deoxy-

10 Rainsford KD. Microvascular injury during gastric mucosal damage by antiinflammatory drugs in pigs and rats. Agents and Actions 1983; 13: 5-6.

11 Ito $M$, Guth PH. Role of oxygen-derived free radicals in hemorrhagic shock-induced gastric lesions in the rat. Gastroenterology 1985; 88: 1162-7.

12 Perry MA, Wadhwa S, Parks DA, Pickard W, Granger DN Role of oxygen radicals in ischemia-induced lesions in the cat stomach. Gastroenterology 1986; 90: 362-7.

13 Tappel AL. Lipid peroxidation damage to cell components. Fed Proc 1973; 32: 1870-4.

14 Yoshikawa T, Miyagawa H, Yoshida N, Sugino S, Kondo M Increase in lipid peroxidation in rat gastric mucosal lesions induced by water-immersion restraint stress. $\mathcal{F}$ Clin Biochem Nutr 1986; 1: 271-7.

15 Yoshikawa T, Yoshida N, Miyagawa H, Takemura T, Tanigawa T, Sugino S, Kondo M. Role of lipid peroxidation in gastric mucosal lesions induced by burn shock in rats. $\mathcal{f}$ Clin Biochem Nutr 1987; 2: 163-70.

16 Yoshikawa T, Ueda S, Naito Y, Takahashi S, Oyamada H, Morita $\mathrm{Y}$, et al. Role of oxygen-derived free radicals in gastric mucosal injury induced by ischema or ischemiareperfusion in rats. Free Radic Res Comms 1989; 7: 285-91.

17 Miyagawa H, Yoshikawa T, Tanigawa T, Yoshida N, Sugino $S$, Kondo M. Measurement of serum superoxide dismutase activity by elec

18 Yagi K. A simple fluorometric assay for lipid peroxides in blood plasma. Biochemical Medicine 1976; 15: 212-6.

19 Ohkawa H, Ohnishi N, Yagi K. Assay for lipid peroxides for animal tissues by thiobarbituric acid reaction. Anal Biochem 1979; 95: 351-8
20 Lowry OH, Rosenbrough NJ, Farr AL, Randall RJ. Protein measurement with the folin phenol reagent. $\mathcal{F}$ Biol Chem 1951; 193: 265-75.

21 Abe KY, Yuguchi Y, Katsui G. Quantitative determination of tocopherols by high-speed liquid chromatography. $\mathcal{F}$ Nutr Sci Vitaminol (Tokyo) 1975; 21: 183-8.

22 Richmond $W$. Preparation and properties of a cholesterol oxidase from Nacardia sp and its application to the enzymatic assay of total cholesterol in serum. Clin Chem 1973; 19: 1350-6.

23 Nakano $M$, Kimura $H$, Hara $M$, Kuroiwa $M$, Kato $M$, Totsune $\mathrm{K}$, Yoshikawa T. A highly sensitive method for determining both $\mathrm{Mn}$ - and $\mathrm{Cu}-\mathrm{Zn}$ superoxide dismutase activities in tissue and blood cells. Anal Biochem 1990; 187: 277-80.

24 Günzler WA, Flohe L. Glutathione peroxidase. In: Greenwald $\mathrm{RA}$, ed. CRC handbook of methods for oxygen radical research. Boca Raton: CRC Press 1985: 285-90.

$25 \mathrm{Griffith}$ OW. Determination of glutathione and glutathione disulfide using glutathione reductase and 2-vinylpyridine. Anal Biochem 1980; 106: 207-12.

26 Cochran T, Stefanko J, Moore C. Dimethylsulfoxide protection against gastric stress ulceration. Current Surg 1983; Nov-Dec: $435-7$

27 Terano A, Hiraishi H, Ota S, Shiga J, Sugimoto T. Role of superoxide and hydroxyl radicals in rat gastric mucosal injury induced by ethanol. Gastroenterol $\mathrm{fp}_{\mathrm{p} n} 1989$; 24 : 48893.

28 Wallace JL, Kennan CM, Granger DN. Gastric ulceration induced by non-steroidal anti-inflammatory drugs is a neutrophil-dependent process. Am $\mathcal{J}$ Physiol 1990; 259;

29 Wallace JL, Arfors K-E, McKnight W. A monoclonal antibody against the CD18 leukocyte adhesion molecule prevents indomethacin-induced gastric damage in the rabbit. Gastroenterology 1991; 100: 878-83.

30 Suzuki M, Inauen W, Kvietys PR, Grisham MB, Meininger C, Schelling ME, et al. Superoxide mediates reperfusioninduced leukocyte-endothelial cell interactions. $A m \mathcal{F}$ Physiol 1989; 257: H1740-5.

31 Sekizuka E, Benoit JN, Grisham MB, Granger DN. Dimethylsulfoxide prevents chemoattractant-induced leukocyte adherence. Am f Physiol 1989; 256: leukocyte

32 Yoshikawa $T$, Yasuda $M$, Ueda $S$, Naito $Y$, Tanigawa $T$, Oyamada $\mathrm{H}$, et al. Vitamin $\mathrm{E}$ in gastric mucosal injury induced by ischemia-reperfusion. Am $\mathcal{F}$ Clin Nutr 1991; 53 : $210 \mathrm{~S}-4 \mathrm{~S}$

33 Niki E, Komura E, Takahashi M, Urano S, Ito E, Terao K. Oxidative hemolysis of erythrocytes and its inhibition by free radical scavengers. $\mathcal{F}$ Biol Chem 1988; 263: 19809 14.

34 Boyd SC, Sasame HA, Boyd MR. High concentration of glutathione in glandular stomach: possible implications for glutathione in glandular stomach: possible

35 Boyd SC, Sasame HA, Boyd MR. Gastric glutathione depletion and acute ulcerogenesis by diethylmaleate given subcutaneously to rats. $L$ ife $S$ ci $1981 ; 28: 2987-92$

36 Mutoh H, Hiraishi H, Ota S, Yoshida H, Ivey KJ, Terano A et al. Protective role of intracellular glutathione against ethanol-induced damage in cultured rat gastric mucosa cells. Gastroenterology 1990; 98: 1452-9.

37 Younes M, Siegers CP. Mechanistic aspects of enhanced lipid peroxidation following glutathione depletion in vivo. Chem Biol Interact 1981; 34: 257-66.

38 Comporti M. Biology of disease: lipid peroxidation and cellular damage in toxic liver injury. Lab Invest 1985; 53: 599-623.

39 Baneriee RK. Nonsteroidal anti-inflammatory drugs inhibit gastric peroxidase activity. Biochim Biophys Acta 1990; 1034: 275-80. 